\title{
Developing Content-Based Criteria for EFL Textbooks: The Case of Iranian Junior \& Senior High School Levels
}

\author{
Mohsen Masoomi ${ }^{1}$, Vida Rahiminezhad ${ }^{2}$ \& Gholam-Reza Abbasian ${ }^{3}$ \\ ${ }^{1}$ Department of English Language, Sanandaj Branch, Islamic Azad University, Sanandaj, Kurdistan, Iran \\ ${ }^{2}$ Research Institute for Education and Iranian Association for Sociology of Education, Tehran, Iran \\ ${ }^{3}$ Imam Ali University and Islamic Azad University, South Tehran Branch, Tehran, Iran \\ Correspondence: Mohsen Masoomi, Department of English Language, Islamic Azad University, Sanandaj, \\ Kurdistan, Iran. Tel: 98-912-871-4077. E-mail: masoomi.mohsen@outlook.com
}

Received: October 6, 2016

Accepted: October 27, 2016 Online Published: December 1, 2016

doi:10.5539/ijel.v6n7p105

URL: http://dx.doi.org/10.5539/ijel.v6n7p105

\begin{abstract}
Images are part of the content of the English textbooks and since junior high school curriculum is currently being underdevelopment, developing criteria for the images of the content of high school textbooks needs attentive consideration. The images need to be chosen according to the needs of students and those objectives found at the higher level documents. This research is conducted based on mixed approach in which students' need is surveyed and data gathered by sifting through the higher level documents. Also, exploring the goals and objectives of the higher level documents, the criteria are obtained and determined by which the content was developed. In addition, the Delphi method is applied to measure the validity of the developed content. The study population at this research consisted of all students in the seventh grade (the first grade of high school), the third grade Secondary School and the first grade high school in five provinces of Iran, including Tehran, Semnan, Kurdistan, Khuzestan and East Azerbaijan counting 394 boys and 396 girls who completed the questionnaire. Also, 10 accessible experts and practitioners in English curriculum participated in developing and validating the criteria. One of the findings of this research indicates that 321 students interested in real images at the first rank and 306 other students fascinated with colored ones, at the second rank respectively.
\end{abstract}

Keywords: curriculum, content, the higher level documents, need and interest of students

\section{Introduction}

\subsection{Statement of the Problem}

In the realm of language acquisition a considerable number of language scholars have maintained the substantial role of textbooks, alongside with that of teachers and learners. The predominant function of content in relation to curriculum design has been viewed from the perspective of a traditional domain where the situational model of curriculum is built upon four major elements of content, objectives, methods and evaluation (Wright, 1989). Since English is taught as a foreign but not a second language in Iran, classroom serves as the essential source of exposure to English for students. So, textbook play an important role in exposing the students to the English Language (Dudley-Evans \& St John, 2000). It means that the textbook which determines the classroom activates, influences teachers' teaching methods, and student's roles. Richards (2007) notes that materials provide the main input for the students and the type of the "language practice that occurs in the classroom."

Another point is that ESL students have very different needs because of differences in cultural background, age, and previous education (Peck, 2006). One of the most important parts of textbooks is visual aids which is the main concern of this article. Iran's official English language training at schools dates back to the years 1938-1939. Foreign language learning was conducted in education curriculum of Iran where Ministry of Culture supported a group of Iranian and foreign authors to design and develop six-volume set of English books. The textbooks were aimed to be taught to students studying at high schools' six years period (Alavi \& Kheirabadi, 2013).

Commenting on the first English language books of our country, Iran, Forouzandeh (2011) states:

"The collection of English textbooks applied the direct training and reading skill strategy containing a wide 
variety of subjects. The six designed textbooks didn't follow a coherent methods of learning, and teaching procedures were not the same in each lesson in a way that it seemed a lesson introduces a piece of literary text lacking any practice and exercise while another lesson contains only grammatical materials related/unrelated to the previous or subsequent lessons."

This series of books were taught about a quarter of a century until 1964 when they are replaced with a new series of books called E-graded (Note 1). The authors of the new textbooks series tried to apply shifts to such traditional teaching methods as direct method in the mainstream of that period, especially Audio-Lingual Method (ALT) and Situational Language Teaching (SLT) and follow the developments in language teaching methods of the time in the content of the written books. This set of books was taught even after the Islamic Revolution when they were later replaced by another set of books at 1982 (Alavi \& Kheirabadi, 2013).

Forouzandeh (2011) discusses in detail the changes and developments in textbooks and also English teaching methods at high schools in his paper. He investigate the changes occurred in periods from 1982 to1990 and 1991to2003. These periods are those which are used in his study at the time of composing the paper. According to Forouzandeh, one of the major shortcomings of the Iranian English-language books in different period of time and levels is the lack of grand policy in the field of English language teaching in the educational system of our country. Since the education system is currently divided into four periods of three years, content of textbooks, especially English language books, will also change gradually to comply with the new system. Since the content of the secondary and high school textbooks have some complications, images needs to be chosen properly. The selection of the images should be based on the on scientific findings and objective data in order to meet the educational objectives. The methodology of this research is based on the mixed approach. A researcher made survey was used to conduct the needs assessment, and then the criteria are developed based on theoretical issues and needs of students while Delphi method is used to measure the validity of the planned content.

\subsection{Significance of the Problem}

Developing criteria for the content of the English textbook in foreign language learning curriculum in the first three years of high school period according to the views of experts and those of students seems essential. Defining these criteria is the main goal of this study. Of course, the overall objectives are developed by considering and reviewing several special purposes as indicators or indexes and involved variables as follows:

Specific goals:

- Identifying the appropriate congruence between the content and learner

- The criteria outlined in the higher level documents

- $\quad$ Authorization of the developed criteria for the English language textbooks

\subsection{Theoretical Framework}

With regard to the characteristics of the educational system in Iran, four variables are discussed in this paper, including: curriculum, content, need and interest of the students and the higher level documents.

\subsubsection{Curriculum}

Curriculum is an educational program which states the educational purpose of the program, the content, teaching procedures and learning experience that is be necessary to meet the aims and provides some means to assess whether or not the educational ends have been achieved (Richards et al., 1992).

There is no consensus among lesson planners about the constituent elements of the curriculum. Some theorists of curriculum designing considering the traditional perspective, focus on the four basic elements of content, objectives, methods and evaluation (Wright, 1989) and others like Frances Klein has developed it up to 9 elements (Klein, 1991). However, a remarkable number of those involved in the curriculum designing emphasizes on substantial function of indicators such as "goals, content, instructional materials, teaching-learning strategies, time-space-evaluation" (Maleki, 1997).

\subsubsection{Content}

Nunan (2003) notes that textbook is the main element of any curriculum and "it is difficult to imagine a class without books..." It is the textbook which "offers a coherent syllabus, satisfactory language control..." (Harmer, 2002). Robinson (1991) believes that textbooks provide "a Framework for a course, and forming in essence a syllabus."

Content is the use of subject matter for second language teaching purposes. Subject matter may consist of topics or themes selected for student interest or need... (Snow, 2006). It can be claimed that the textbook contains the 
educational content; thus, compiling textbooks is synonymous with developing content according to scientific methods and principles. Picture is among one of the factors that are strongly considered in developing textbooks' content.

\subsubsection{Visual Aids}

Wright (1989) believed that the outside world should be shown in the class. He proposed that the new language associated with these representations would be more comprehensible, if students can link the reference and representation to the outside world. Visual aids can convey nonverbal information. Nunan (2003) asserts that different types of visual aids such as pictures, drawings, photos can be used in a textbook.

Selecting the beautiful images in relation with concepts and contents of the textbook is another step in developing appropriate content. A good meaningful picture sometimes can contribute more to learning than texts. Especially, objective learning through visual images is more effective in elementary level because pictures and images are more influential and inspiring. However, the images must be selected with care and consideration. Selected photos may be sometimes irrelevant to the other components of the content and accordingly does not contribute to the learning process (Maleki, 1997).

\subsubsection{The Higher Level Documents}

The higher level documents in this study is the national curriculum, including the curricula and educational and training principles of ministry of education at Islamic Republic of Iran designed in line with Islamic-Iranian culture, with an emphasis on precious and lasting legacy of Mohammad, the Prophet (pbuh), the holy Quran and progeny, the realization of justice of Imam Mahdi (A.S.) and The Future Outlook of the Islamic Republic of Iran in the Horizon of the Next Two Decades or 2025 (2003).

\subsubsection{The Needs}

Textbook writing is a prodigious task. First there is a need to carry out "needs analysis" in order to specify in detail what and how the material should be selected, graded, and sequenced (Farhady, 2005). Jordan (1997) notes that there are a number of variables need to betake care in materials writing which are students, teachers, syllabus, methodology, resources, time, and finance." The most important thing is to gather enough information about the students: their levels, age, learning styles and strategies, cultural and social background, needs, wants, objectives, and preferences. Masuhara (2006) states that "effective materials cannot be made without valid use of visuals..." Meanwhile, Cunnings worth (1995) declares that using visuals "provides meaningful contexts" and therefore enhances language learning.

\section{Method}

The methodology of this research is based on the mixed approach; a survey was used to gather the needs of students and the higher level documents were explored to find the existing criteria through which the visual elements of textbook are designed. Next, Delphi method is used to measure the validity of the planned content.

\subsection{Data Collection Tools}

1) A researcher-made questionnaire for needs assessment of students

2) Open questionnaire to survey the experts in the field of English language and curriculum plan and specialists in teaching English

Some specialists ideas are asked to authenticate the content validity. Reliability equals to reliability and stability. Determining the variance of the questionnaire and measuring the reliability of the tools in this study, the research tools were conducted for 30 people of the research population, and calculated Cronbach alpha coefficient was 0.75 .

\subsection{Data Analysis Methods}

A mixed approach used in this study consists of Delphi and survey approach.

A. The survey explores the views of students in regarding to the content:

1) The degree of students' interest to textbooks content is surveyed by a questionnaire completed by the students.

2) Data analysis is based on the descriptive method, so that data obtained from the questionnaires analyzed in percentage frequency tables of data to display and illustrate the inclusive representation of the gathered data.

A. Using a theory based survey relying on the gathered research data.

B. Finally, using the Delphi method, curriculum planning and teaching English experts and specialist's notions is surveyed and the designed content was discussed and credited. 


\subsection{Research population}

A. Specialists and practitioners in the field of ELT and curriculum designing specialists of English courses

B. The second and third year Middle school students and the first year High school students

a) The number of students in the second and third year studying in the urban area in 2010-2011 educational circle is 2,173,151 people.

b) The number of first year high school students in 2010-2011 educational year is 954,927.

\subsection{Sample Size Determination}

\subsubsection{Sample Size of Students}

The standard deviation in the population of students in similar research studies (second and third grades in the middle and high schools) is 0.8 in Likert scale show. Since the researchers are interested in the accuracy of results with less than 0.1 error, a sample size of 250 students will suffice to ensure 0.95 accuracy and precision, (with respect to predicting the likelihood of incomplete questionnaire) sample size for each group of male and female students is estimated as 300 people.

$$
\mathrm{n}=\frac{z^{2} s^{2}}{\mathrm{~d}^{2}}=\frac{(1.96)^{2}(.8)^{2}}{(.1)^{2}}=250
$$

\subsubsection{Experts}

Curriculum specialists and experts in the field of ELT at Iran's universities are approximately estimated as 10 people.

\section{Results}

In this section, students' responses to the questionnaire regarding the "criteria for appropriateness of image content with learners and their condition" are studied:

\subsection{Students' Needs and Interests from Their Viewpoint}

The total number of sampled students in Kurdistan, East Azerbaijan, Tehran, Khuzestan and Semnan provinces were 790 of which $49.9 \%$ (394 people) are boys and 50.1 percent (396) were girls.

Table 1. Students' favorite images

\begin{tabular}{lllllllll}
\hline \multirow{2}{*}{$\begin{array}{l}\text { The } \\
\text { Order }\end{array}$} & \multirow{2}{*}{$\begin{array}{l}\text { Weights for the } \\
\text { selected ratings }\end{array}$} & \multicolumn{2}{l}{ The first choice } & \multicolumn{2}{l}{ The second choice } & \multicolumn{2}{l}{ The third choice } & \\
\cline { 2 - 7 } & Percentage & Frequency & Percentage & Frequency & Percentage & Frequency & Type of images \\
\hline 1 & 321 & $26.9 \%$ & 2 & $33.3 \%$ & 14 & $39.9 \%$ & 97 & Real \\
3 & 165 & $28.8 \%$ & 3 & $50.0 \%$ & 15 & $18.1 \%$ & 44 & $\begin{array}{l}\text { Animation } \\
\text { (cartoon) }\end{array}$ \\
& & & & & & & & Artistic \\
2 & 41 & $13.5 \%$ & 0 & $0.0 \%$ & 7 & $3.7 \%$ & 9 & Colored \\
& 306 & $30.8 \%$ & 1 & $16.7 \%$ & 16 & $37.4 \%$ & 91 & Sum \\
\hline
\end{tabular}

Table 1 examines the first part of the second phase of students' responses to the question below: "What images and photos would you like to be inserted in English textbooks?" At this stage, the column at the table entitled "image type" is divided into to four subcategories including, "real, animation (cartoon), artistic and colored". Total responses of students to all the subcategories at the first choice are 243,52 to the second and 6 to the third choice respectively. Taking into account the factors and also calculating the weighted sum of the priorities, the table's top priority is dedicated to the category titled "real images." As it is shown in the table, the frequency of the students who are interested in this subcategory is 79 out of 243 students responded to all 4 subcategories in the first priority. 14 out of 52 respondents in the second priority and 2 out of 6 are found in the third priority that eventually was ranked at the first place with a total weight of 321. Subcategories of "Arts subjects" shows the frequency of 9 out of 243 in all 4 sub-categories in the first priority and 7 out of 52 in the second priority with total weighting coefficient of 41 ranked at the last column of the table. 
Table 2. Students' favorite image

\begin{tabular}{|c|c|c|c|c|c|c|c|c|}
\hline \multirow{2}{*}{$\begin{array}{l}\text { The } \\
\text { Order }\end{array}$} & \multirow{2}{*}{$\begin{array}{l}\text { Weights for } \\
\text { the selected } \\
\text { ratings }\end{array}$} & \multicolumn{2}{|c|}{ The First Priority } & \multicolumn{2}{|c|}{ The Second Priority } & \multicolumn{2}{|c|}{ The Third Priority } & \multirow[t]{2}{*}{ Images } \\
\hline & & Frequency & Percentage & Frequency & Percentage & Frequency & Percentage & \\
\hline 10 & 30 & 6 & $2.3 \%$ & 6 & $5.2 \%$ & 0 & $0.0 \%$ & Food \\
\hline 1 & 236 & 69 & $26.0 \%$ & 12 & $10.4 \%$ & 5 & $16.1 \%$ & Nature and animals \\
\hline 3 & 150 & 38 & $14.3 \%$ & 15 & $13.0 \%$ & 6 & $19.4 \%$ & Sport and Exercise \\
\hline 7 & 65 & 17 & $6.4 \%$ & 6 & $5.2 \%$ & 2 & $6.5 \%$ & Social events (conversations) \\
\hline 6 & 75 & 16 & $6.0 \%$ & 12 & $10.4 \%$ & 3 & $9.7 \%$ & Famous People \\
\hline 11 & 20 & 4 & $1.5 \%$ & 3 & $2.6 \%$ & 2 & $6.5 \%$ & Cultural or religious ceremony \\
\hline 4 & 90 & 24 & $9.1 \%$ & 8 & $7.0 \%$ & 2 & $6.5 \%$ & jobs \\
\hline 11 & 20 & 2 & $0.8 \%$ & 6 & $5.2 \%$ & 2 & $6.5 \%$ & Art objects \\
\hline 5 & 77 & 17 & $6.4 \%$ & 12 & $10.4 \%$ & 2 & $6.5 \%$ & Science and history \\
\hline 8 & 59 & 12 & $4.5 \%$ & 10 & $8.7 \%$ & 3 & $9.7 \%$ & Famous places and sights \\
\hline 2 & 177 & 47 & $17.7 \%$ & 17 & $14.8 \%$ & 2 & $6.5 \%$ & Cartoon, fun and caricature \\
\hline 9 & 48 & 11 & $4.2 \%$ & 7 & $6.1 \%$ & 1 & $3.2 \%$ & $\begin{array}{l}\text { Other objects, cars, family } \\
\text { environment }\end{array}$ \\
\hline
\end{tabular}

Table 2 examines and addresses the students' responses to the second round of question indicating "What types of images in English textbooks would be your favorite?" At this stage the class entitled "Favorite Images of Students" is divided into 12 subcategories. Total student responses to each of the 12 sub- categories are 265 in the first priority, 115 and 31 in the second and the third priority respectively. Taking into account the factors and also calculating the weighted sum of the priorities, the table's top priority is dedicated to the category titled "Nature and Animals." As it is shown in the table, the frequency of the students who are interested in this subcategory is 69 out of 265 students responded to all 12 subcategories in the first priority. 12 out of 115 respondents in the second priority and 5 out of 31 are found in the third priority that eventually was ranked at the first place with a total weight of 236. Subcategories of "cultural or religious ceremony" and "art Subjects" with total weighting coefficient of 20 was ranked at the equal order and both subcategories are ranked in 11th ranking place.

Because of the close similarity between the favorite subjects and affinity of students' perspectives in all three grades of seven, eight and nine at the first period of high school education, their ideas about the needs and interests of students are divided into 6 groups with associated subcategories which are identified in the table 1-1.

\subsection{Criteria for the Content of English Textbooks in Higher Level Documents: Reviewing the Documents in the Field of Foreign Languages}

\subsubsection{The Higher Level Documents}

The higher level documents in this study are The Future Outlook of the Islamic Republic of Iran in the Horizon of the Next Two Decades or 2025 (2003) and the national curriculum, including the curricula and educational and training principles of ministry of education at Islamic Republic of Iran designed in line with Islamic-Iranian culture, with an emphasis on precious and lasting legacy of Mohammad, the Prophet (pbuh), the holy Quran and progeny, the realization of justice of Imam Mahdi (A.S.)

A. The Future Outlook of the Islamic Republic of Iran in the Horizon of the Next Two Decades (2025)

"Iran is a developed country owning the first place in economic development, and science and technology in the region. Iranis a country with Islamic and revolutionary identity inspiring the Muslim world and engaging constructively and effectively in international relations."

B. Characteristics of educational curricula and training based on the visions of the public education system in The Future Outlook of the Islamic Republic of Iran in the Horizon of the Next Two Decades or 2025 (2003) includes appropriateness to the principles and values and teachings of Islam represented by the prophet Muhammad (pbuh), enjoying the valid scientific findings and research with an emphasis on domestication of the findings. It should be benefitting from the scientific achievements and findings of Islamic -Iranian culture and civilization. The curriculum should be interconnected, well-adjusted, efficient, spirited, dynamic, flexible and participatory in both production and administration. It should refer to the characteristics, needs and students' divine nature and the basic needs of society. It needs to be benefited from national and international fruitful experiences by using the tools and scientific and effective methods. It needs to be benefited from an innovative approach, the future scholarship and it needs to be realistic, according to the divine nature of man. Emphasizing on the role of the school as a manifestation of pure life and underlying the realization of justice of Imam Mahdi (A.S.), as well as the main focus on the curriculum and educational goals. 
C. The principles governing the content of the curriculum as one of the elements of the Iranian National Curriculum (2012) includes "religious-based", "national identity", "reliability of the learner", "authority of the teacher (trainer)" "recognition of the structure of the family", "holistic (Note 2)", "respect to the dissimilarities (Note 3)", "lifelong learning", "participation and engagement", "integration and learning (Note 4)".

The required criteria, students' needs and standards and criteria endorsed in the higher level documents is organized in a table and offered to curriculum designing specialists and experts in the field of EFL education to be authenticated and validated. Experts' responses at each level was collected, applied and sent back to them to receive the final endorsement. Finally, the suggested criterion to develop and design the curriculum of the English textbooks was offered.

Applying experts' concepts and ideas regarding the findings and receiving the almost confirmation of all specialists, the criteria for compiling the English language textbooks for the student in the first year of high school were developed, as it is shown in the below table.

Table 3. The pictures' criteria coordinated with the higher level documents and needs of learners at the first grade at high school

\begin{tabular}{|c|c|c|}
\hline Sub-criteria & Indicator & Reference \\
\hline & $\begin{array}{l}\text { - It should be developed based on the principles and values and teachings of Islam represented by the } \\
\text { prophet Muhammad (pbuh). } \\
\text { - The valid scientific findings and research with an emphasis on domestication of the findings are stressed. } \\
\text { - It should be benefitting from the scientific achievements and findings of Islamic -Iranian culture and } \\
\text { civilization. } \\
\text { - The curriculum should be interconnected, well-adjusted, efficient, spirited, dynamic, flexible and } \\
\text { participatory in both production and administration. } \\
\text { - It should refer to the characteristics, needs and students' divine nature and the basic needs of society. } \\
\text { - It needs to be benefited from national and international fruitful experiences by using the tools and } \\
\text { scientific and effective methods. } \\
\text { - It needs to be benefited from an innovative approach, the future scholarship and it needs to be realistic, } \\
\text { according to the divine nature of man. } \\
\text { - Emphasizing on the role of the school as a manifestation of pure life and underlying the realization of } \\
\text { justice of Imam Mahdi (A.S.), as well as the main focus on the curriculum and educational goals. }\end{array}$ & $\begin{array}{l}\text { The Future } \\
\text { Outlook of the } \\
\text { Islamic Republic } \\
\text { of Iran in the } \\
\text { Horizon of the } \\
\text { Next Two decades } \\
\text { or } 2025\end{array}$ \\
\hline $\begin{array}{l}\text { The } \\
\text { appropriatene } \\
\text { ss of the } \\
\text { pictures with } \\
\text { the higher } \\
\text { level } \\
\text { documents }\end{array}$ & $\begin{array}{l}\text { - proportional to the faith and religious believes } \\
\text { - proportional to national identity } \\
\text { - proportional to the role of the learner } \\
\text { - consideration to the integration and learning } \\
\text { - consideration to the participation of students } \\
\text { - consideration to the differences } \\
\text { - proportional to the cultural and educational values } \\
\text { - commensurate with social interactions (interactions between human societies and the development of IT } \\
\text { - proportional to interpersonal and intercultural relationship } \\
\text { - consideration to economic development (tourism, trade, technology) } \\
\text { - consideration to the development of science } \\
\text { - consideration to the socio-political consciousness } \\
\text { - the effective and fruitful international communication } \\
\text { - consideration to the local issues } \\
\text { - creating opportunities to link theory and practice } \\
\text { - utilization of active, creative and enlightening methods } \\
\text { - establishing the effective interaction of students with teachers, peers and the different kinds of learning } \\
\text { environments } \\
\text { - consideration to development of scienc }\end{array}$ & $\begin{array}{l}\text { National } \\
\text { Curriculum } \\
\text { Document (2012) }\end{array}$ \\
\hline \multirow{3}{*}{$\begin{array}{l}\text { The } \\
\text { appropriatene } \\
\text { ss of the } \\
\text { pictures with } \\
\text { students' } \\
\text { needs and } \\
\text { interest of }\end{array}$} & $\begin{array}{l}\text { - considering the health care needs of students. } \\
\text { - considering the health of students } \\
\text { - considering the daily life of students } \\
\text { - considering the surrounding environment for students, } \\
\text { - investigating constant needs of students }\end{array}$ & $\begin{array}{l}\text { National } \\
\text { Curriculum } \\
\text { Document (2012) }\end{array}$ \\
\hline & $\begin{array}{l}\text { The kind of images are ordered based on the priority: } \\
\text { Real } \\
\text { Colored } \\
\text { Animation } \\
\text { Art }\end{array}$ & $\begin{array}{l}\text { Students' } \\
\text { Questionnaire }\end{array}$ \\
\hline & $\begin{array}{l}\text { The subjects of images are ordered based on the priority: } \\
\text { Nature and animals } \\
\text { - cartoon, fun and caricature } \\
\text { - sport and exercise } \\
\text { - jobs } \\
\text { - scientific and historical subjects } \\
\text { - famous people } \\
\text { - social events } \\
\text { - landmarks and sights }\end{array}$ & \\
\hline
\end{tabular}




\section{Discussion}

Iran's education system is centralized. It is developing based on considering the higher level documents (The Future Outlook of the Islamic Republic of Iran in the Horizon of the Next Two Decades, 2025). This system is currently changing from the old educational system including 5 years of primary school, 3 years of secondary school, three years of high school and one year of pre-university period to four three-year periods $(3,3,3,3)$. Due to changes in the education system, new textbooks should be written in accordance with the procedures set forth in the higher level documents. Thus, according to the objectives of the higher level documents as well as the needs and interests of the junior high school students, the criteria for selecting images of textbooks were developed. The criteria can be used to compile English language textbooks to achieve educational purposes indicated in the higher level documents.

\section{Acknowledgments}

The main research project from which this paper is reported was funded by the Deputy of Research and Technology, Islamic Azad University, Sanandaj Branch, Kurdistan, Iran.

\section{References}

Alavi, S. B., \& Kheirabadi, R. (2013). The Policy of Teaching Foreign Languages in National Curriculm. Roshd FLT, 27(4).

Cunningsworth, A. (1995). Choosing your course book. Oxford: Heinemann.

Dudley-Evans, T., \& St John, M. J. (2000). Developments in English for specific purposes: A multidisciplinary approach. Cambridge: Cambridge University Press.

Farhady, H. (2005). Reflections on and directions for ESP materials development. In G. R. Kiany \& M. Khayamdar (Eds.), Proceedings of the First National ESP/EAP Conference, 3(2-32). Tehran: SAMT.

Forouzandeh, E. (2011). History of High School English Course Books in Iran: 1318-1389 (1939-2010). Roshd FLT, 26(1), 57-69.

Harmer, J. (2002). The Practice of English Language Teaching. Harlow: Longman.

Iranian National Curriculum Document. (2012). Ministry of education. Iran, Tehran.

Jordan, R. R. (1997). English for academic purposes: A guide and resource book for teachers. Cambridge: Cambridge University Press. http://dx.doi.org/10.1017/CBO9780511733062

Klein, M. F. (1991). The Politics of curriculum decision-making: Issues in centralizing the curriculum. Albany: State University of New York Press.

Maleki, H. (1997). Curriculum Designing (guidelines). Tehran: School Publications.

Masuhara, H. (2006). Materials as a teacher development tool. In J. Mukundan (Ed.), Readings on ELT materials (vol. II, pp. 34-46). Malaysia: Pearson Longman.

Nunan, D. (2003). Practical English language teaching. New York: McGraw-Hill Companies, Inc.

Peck, S. (2006). Recognizing and Meeting the needs of ESL Students. Teaching English as a Second or Foreign Language. Michigan, US: University of Michigan Press.

Richards, J. C. (2007). Curriculum development in language teaching (8th printing). New York: Longman.

Richards, J. C. et al. (1992). Longman Dictionary of Language Teaching and Applied Linguistics (2nd ed.). Harlow, Essex: Longman Group UK Limited.

Robinson, P. C. (1991). ESP today: A Practitioner's Guide. Hemel Hempstead: Phoenix.

Snow, M. A. (2006). Teaching Language through Content. Teaching English as a Second or Foreign Language. Michigan, US: University of Michigan Press.

The office of Iran's supreme leader. (2003). The Future Outlook of the Islamic Republic of Iran in the Horizon of the Next Two Decades or 2025.

Wright, A. (1989). Pictures for language learning. Cambridge: Cambridge University Press. 


\section{Notes}

Note 1. Graded English.

Note 2. Curricula and training should stress on the diverse needs of students and society at the local, regional, national and worldwide range comprising the whole realm of education.

Note 3. Emphasizing on the common features, principles should be flexible enough to consider the differences caused by environment (urban, rural, tribal, cultural, and geographical), gender and individuality (talents, abilities, needs and interests).

Note 4. Curricula and training should be designed based on the needs of all students (regular students, students with special needs and gifted students). They should be development interconnected and integrated. These programs must comply with flexibility, the needs of each group of students with special needs and talents.

\section{Copyrights}

Copyright for this article is retained by the author(s), with first publication rights granted to the journal.

This is an open-access article distributed under the terms and conditions of the Creative Commons Attribution license (http://creativecommons.org/licenses/by/4.0/). 